\title{
Acute non-invasive ventilation - getting it right on the acute medical take
}

\author{
Authors: Dipansu Ghosh ${ }^{A}$ and Mark W Elliott ${ }^{B}$
}

Non-invasive ventilation (NIV) given to the right patient, in the right setting, in the right way and at the right time improves outcomes. However, national audits reveal poor practice in patient selection, clinical judgement, treatment initiation and availability of trained staff. NIV is indicated for persistent acute hypercapnic respiratory failure (AHRF) with acidosis after usual medical management in chronic obstructive pulmonary disease (COPD) exacerbation and even without acidosis in neuromuscular disorders or other restrictive conditions eg obesity hypoventilation or kyphoscoliosis. Having trained staff in a suitable environment with adequate equipment are keys to its success, along with close monitoring. A plan should be put in place at the time of initiating NIV about the ceiling of care, eg escalation to intubation or palliation, if the patient is not improving with NIV. Early NIV failure is most likely due to technical issues, such as inadequate pressures or mask leak, while late failure is usually the consequence of advanced disease. Any presentation with AHRF is a poor prognostic indicator and outpatient respiratory follow-up is indicated following discharge. For selected patients with COPD who remain hypercapnic 2 weeks after an exacerbation, domiciliary NIV can reduce admissions and improve survival. For patients with neuromuscular disorders or kyphoscoliosis a presentation with AHRF almost always indicates the need for domiciliary NIV.

\section{Introduction}

Non-invasive ventilation (NIV) applied to the right patient, in the right setting, in the right way and at the right time improves outcomes. British Thoracic Society (BTS) quality standards dictate that all patients who meet the criteria should receive acute NIV and all hospitals should have adequate capacity to provide an effective service. ${ }^{1}$ National audits ${ }^{2,3}$ and a National Confidential Enquiry into Patient Outcome and Death (NCEPOD) ${ }^{4}$ on the application of acute NIV raise several concerns.

These include poor patient selection, delay in initiating treatment (due to organisational issues and a failure by the

Authors: A consultant in respiratory medicine, St James's University Hospital, Leeds, UK; ${ }^{\text {B }}$ consultant in respiratory medicine, St James's University Hospital, Leeds, UK treating clinician to recognise that NIV indicated), ineffective treatment delivery, availability of competent staff and monitoring of progress.

\section{Key points}

\section{Right patient}

Acute non-invasive ventilation in acute hypercapnic respiratory failure can reduce intubation rate and improve survival in chronic obstructive pulmonary disease exacerbation, respiratory decompensation due to neuromuscular conditions and restrictive ventilatory conditions eg obesity hypoventilation syndrome, kyphoscoliosis.

Non-invasive ventilation is only indicated for treatment of hypoxaemic respiratory failure in an intensive care unit setting where advanced monitoring and emergency intubation and ventilation is available.

Acute hypercapnic respiratory failure may be the first presentation of undiagnosed neuromuscular conditions (eg motor neurone disease) or other restrictive conditions (eg obesity hypoventilation syndrome, kyphoscoliosis).

The possibility of acute hypercapnic respiratory failure should be considered in any hospitalised patient with neuromuscular disorder, chest wall deformity or obesity.

Any patient with acute hypercapnic respiratory failure should be referred to a specialist for advice about ongoing management.

\section{Right environment}

Non-invasive ventilation should be started in an area where staff have had adequate training and equipment.

\section{Right way}

Starting inspiratory positive airways pressure should be set at $15 \mathrm{~cm} \mathrm{H}_{2} \mathrm{O}$ with rapid titration upwards depending on clinical response including respiratory rate, $\mathrm{SpO}_{2}$ (targeted to a value between 88 and $92 \%$ ), $\mathrm{PaCO}_{2}$ and $\mathrm{PaO}_{2}$.

KEYWORDS: NIV, respiratory failure, COPD, neuromuscular, IPAP 
In this article we focus on conditions that are commonly encountered on an acute medical take for which NIV is indicated.

\section{Right patient}

All patients at risk of hypercapnic respiratory failure should receive oxygen targeted to an oxygen saturation of $88-92 \%$ (Table 1$)^{5}$

\section{Obstructive airways diseases}

NIV is indicated for persistent acute hypercapnic respiratory failure (AHRF; $\mathrm{pH}<7.35$ and $\mathrm{PaCO}_{2}>6 \mathrm{kPa}$ ) due to an acute exacerbation of chronic obstructive pulmonary disease (AECOPD) following immediate medical therapy. It is strongly recommended with a high certainty of the evidence. ${ }^{6,7}$ There is no role for NIV in acute asthma, ${ }^{6,7}$ but given the possibility of overlap between asthma and COPD, NIV may be considered in a sub group of patients diagnosed with asthma but behaving more like patients with COPD (ie with a degree of irreversible airflow obstruction). ${ }^{6}$ Physiologically severe bronchiectasis is usually characterised by airflow obstruction and the same recommendations for NIV in AECOPD should be used. ${ }^{6}$ This should be combined with regular specialist respiratory physiotherapy; physiotherapy treatments may be best delivered after a period of NIV or with breaks for NIV if the patient is very breathless.

\section{Obesity hypoventilation syndrome}

The decision to start acute NIV should be based on the same criteria as for AECOPD, with the exception that NIV can be considered for some hypercapnic patients even in the absence of acidosis. ${ }^{6}$

\section{Neuromuscular disorders and chest wall deformity}

Respiratory muscle weakness is invariable in some neuromuscular disorders (NMDs), eg motor neurone disease, but may occur in any patient with a generalised neuromuscular disease. Even though it may occur rarely in a particular condition (Shahrizaila et al provide a review of respiratory muscle involvement in NMDs) ${ }^{8}$ the possibility of respiratory failure should be considered in any patient with an NMD admitted to hospital with an acute illness. Symptoms can be very non-specific and breathlessness and respiratory distress may be mild or absent. There should be a very low threshold for arterial blood gas analysis. The same is true for a patient with severe chest wall deformity (CWD), most commonly due to early onset scoliosis. Conversely, an undiagnosed NMD should be considered in any patient with unexplained AHRF. ${ }^{9}$

For patients with NMD and normal lungs, hypercapnia only occurs with severe muscle weakness; domiciliary NIV is almost always indicated and NIV should be started acutely if the carbon dioxide is raised. It is not necessary for the patient to be acidotic. NIV should be considered even if the patient is normocapnic, there is a significant reduction in vital capacity and the patient is tachypnoeic. In this situation the patient cannot maintain adequate ventilation indefinitely and the respiratory muscles may fatigue, leading to AHRF. ${ }^{6}$

Table 1. Indications for non-invasive ventilation by aetiology of respiratory failure, level and strength of evidence and implications for domiciliary non-invasive ventilation

\begin{tabular}{|c|c|c|c|}
\hline Condition & Acute indication & $\begin{array}{l}\text { Level and strength of } \\
\text { evidence }\end{array}$ & Implications for domiciliary NIV \\
\hline \multirow[t]{2}{*}{ AECOPD } & \multirow[t]{2}{*}{$\mathrm{pH}<7.35$ and $\mathrm{PaCO}_{2}>6 \mathrm{kPa}$} & $\begin{array}{l}\text { Strong recommendation } \\
\text { with high certainty }{ }^{7}\end{array}$ & \multirow{2}{*}{$\begin{array}{l}\text { Consider domiciliary NIV if } \mathrm{PaCO}_{2}>7 \mathrm{kPa} \\
\text { at least } 2 \text { weeks after first episode of AHRF } \\
\text { requiring NIV }\end{array}$} \\
\hline & & Grade $A^{6}$ & \\
\hline CPO & $\begin{array}{l}\text { Acute respiratory failure }\left(\mathrm{PaO}_{2}\right. \\
<8 \mathrm{kPa} \text { and/or } \mathrm{PaCO}_{2}>6 \mathrm{kPa}\end{array}$ & $\begin{array}{l}\text { Strong recommendation } \\
\text { with moderate certainty }{ }^{7}\end{array}$ & Domiciliary NIV not indicated \\
\hline \multirow[t]{2}{*}{$\mathrm{OHS}$} & $\mathrm{pH}<7.35$ and $\mathrm{PaCO}_{2}>6 \mathrm{kPa}$ & \multirow[t]{2}{*}{ Grade $B^{6}$} & \multirow{2}{*}{$\begin{array}{l}\text { Domiciliary NIV may be indicated. CPAP should } \\
\text { be usual first choice of positive pressure support } \\
\text { unless } \mathrm{PaCO}_{2} \geq 8 \mathrm{kPa} \text {. Chronic respiratory failure } \\
\text { may resolve with treatment of fluid overload }\end{array}$} \\
\hline & $\begin{array}{l}\text { In some cases } \mathrm{PaCO}_{2}>6 \mathrm{kPa} \\
\text { without acidosis }\end{array}$ & & \\
\hline \multirow[t]{2}{*}{ NMD and CWD } & $\mathrm{PaCO}_{2}>6 \mathrm{kPa}$ & \multirow[t]{2}{*}{ Grade $D^{6}$} & \multirow{2}{*}{$\begin{array}{l}\text { Domiciliary NIV almost always indicated } \\
\text { following an episode of hypercapnic respiratory } \\
\text { failure }\end{array}$} \\
\hline & $\begin{array}{l}\text { Normal } \mathrm{PaCO}_{2} \text { with reduced } \\
\text { vital capacity and tachypnoea }\end{array}$ & & \\
\hline Asthma & $\begin{array}{l}\text { Not indicated except in small } \\
\text { subset behaving like COPD }\end{array}$ & Grades $C$ and $D^{6}$ & Usually not indicated but see COPD \\
\hline Bronchiectasis & $\mathrm{pH}<7.35$ and $\mathrm{PaCO}_{2}>6 \mathrm{kPa}$ & Grade $B^{6}$ & See COPD \\
\hline Pneumonia & $\begin{array}{l}\text { NIV not indicated (except in } \\
\text { ICU) }\end{array}$ & $\begin{array}{l}\text { Given uncertainty } \\
\text { of evidence, no } \\
\text { recommendation made }\end{array}$ & \\
\hline $\begin{array}{l}\text { Pneumonia complicating } \\
\text { AECOPD }\end{array}$ & See COPD & & \\
\hline
\end{tabular}




\section{Acute cardiogenic pulmonary oedema}

Patients must receive standard medical therapy, including diuretics and nitrates. Meta-analyse ${ }^{10}$ have shown a reduction in intubation rates and improved survival with NIV (continuous positive airway pressure (CPAP) or bi-level ventilation), which is recommended when patients present with respiratory distress and respiratory failure. ${ }^{7}$ There is no difference between CPAP and bi-level ventilation and CPAP is probably the ventilatory modality of choice, because of greater ease of application. It is important to note that in the Three Interventions in Cardiogenic Pulmonary Oedema trial ${ }^{11}$ there was quicker resolution of the blood gas abnormality and reduction in severe dyspnoea with NIV, but probably at the cost of more discomfort.

\section{Pneumonia and other conditions causing hypoxaemic respiratory failure}

The role of NIV is limited in patients presenting with hypoxaemic respiratory failure, eg pneumonia. However, if a patient with underlying COPD or NMD etc presents with AHRF and coincident pneumonia, a trial of NIV is reasonable. ${ }^{12}$ It is important to make the distinction between pneumonia causing acute respiratory failure and pneumonia complicating a condition known to cause AHRF in its own right (eg COPD or NMD etc).

For example there is a big difference between a COPD patient with severe airways obstruction and a small patch of pneumonia (responds well to NIV) ${ }^{12}$ and a patient with mild/moderate COPD and multi-lobar pneumonia (less likely to respond to NIV and, if they need ventilatory support, they should usually be on intensive care unit (ICU)).

\section{Contraindications}

NIV has few absolute contraindications but these include facial burns and severe facial deformity where physically a mask cannot be applied. Low Glasgow Coma Score (GCS) is not a contraindication, indeed results comparable to those obtained in patients without coma have been reported in patients with a GCS $<8 .^{13}$ The patient must be monitored closely in case of vomiting; the mask must then be removed immediately to reduce the risk of aspiration. If the patient is agitated it must first be ensured that the agitation is not due to inappropriately applied NIV or a poorly fitting mask etc and then low dose sedation can be considered though only in an environment where close monitoring is possible. ${ }^{14}$

\section{Right environment}

Acute NIV for AHRF should be delivered in a clinical area where staff are trained to manage NIV machines, settings and interfaces. ${ }^{4}$ This could be the emergency department (ED), high dependency unit (HDU), ICU or on a ward. A study from Australia showed no difference in outcomes when NIV was delivered on ICU, HDU or a ward. ${ }^{15}$ However, more patients received NIV, which was also more cost effective, in the ward model. Key factors in delivering NIV successfully were daily specialist respiratory input and staff education, training and support. The nurse to patient staffing ratios on the ward were better than would usually be seen in many other health care systems, including the UK (one nurse to four patients during the day and one to eight at night). This study however confirms the importance of the skills of the staff delivering NIV over the location in which it is delivered. The BTS quality standards for acute NIV state that NIV must be delivered in a designated area and that all staff who prescribe, initiate or make changes to acute NIV treatment have evidence of training appropriate to their role and been assessed as competent. ${ }^{1}$ Departments should have a governance mechanism to ensure that this is done when staff start working in the department and that this is maintained. There must be adequate equipment available to meet demand and there should be a choice of masks. The best location will vary from hospital to hospital and will depend upon the skills and experience of the local team, the ability to monitor the patient and the level of staffing. ${ }^{15}$ Factors that need to be taken into account include the severity of the respiratory failure and the early response to NIV. For example a patient with very severe acidosis due to an AECOPD, who responds rapidly to NIV does not need to be managed in a critical care environment, whereas a patient with less severe acidosis, who does not respond to NIV initially, is at higher risk of failure and should be treated in a more intensively monitored and staffed environment. The more severe the physiological disturbance and the less the likelihood of a successful outcome with NIV the more intensive the environment, but this does not necessarily need to be an ICU.

The NCEPOD report showed that in $27 \%$ of patients there was a delay in initiating NIV and recommended that the ED is probably the best place to start NIV. ${ }^{4}$ However in most cases the first focus should be on starting standard medical therapy, including oxygen delivered to a target saturation of 88 to $92 \% ; 20 \%$ of patients presenting with acidosis to the ED correct their $\mathrm{pH}$ within the first hour with these measures alone. ${ }^{16}$

NIV for hypoxaemic respiratory failure should only be applied in an environment where the patient can be intubated rapidly should this be necessary. While hypercapnia develops gradually, hypoxaemia can develop rapidly. Oxygenation can be maintained when the NIV mask is in place but if it is displaced, sudden oxygen desaturation can occur. NIV in this situation can give rise to a false sense of stability; it should not be delivered outside of the ICU.

\section{Right way}

Acute NIV should usually be delivered using a bi-level ventilator through a full face mask starting at inspiratory positive airways pressure (IPAP) of $15 \mathrm{~cm} \mathrm{H}_{2} \mathrm{O}$. The expiratory positive airways pressure (EPAP) should be started at 3 or $4 \mathrm{~cm} \mathrm{H}_{2} \mathrm{O}$ depending on the ventilator specifications followed by up titration every 10-30 minutes, depending on response. The aim should be to maintain oxygen saturation between 88 to $92 \%$, ideally by increasing ventilation rather than increasing the $\mathrm{FiO}_{2}$ and to see an improvement in $\mathrm{pH}, \mathrm{PaCO}_{2}$ and respiratory rate. ${ }^{17,18}$ The patient should be observed closely for signs of patient ventilator asynchrony, excessive use of accessory muscles and mask leakage and discomfort. ${ }^{6}$

Higher levels of IPAP ( 20 to $30 \mathrm{~cm} \mathrm{H}_{2} \mathrm{O}$ ) may be needed in patients with AECOPD, OHS and CWD, but lower pressures may be sufficient in NMDs with no lung parenchymal abnormality. Higher levels of EPAP may be necessary in patients with upper airways obstruction during sleep or OHS (Fig 1). In obstructive conditions, enough time must be allowed for expiration.

Oxygen can be delivered into the mask or the ventilator circuit, in which case it should be positioned as close to the mask as possible. 
Fig 1. Summary for providing acute non-invasive ventilation. $A B G=$ arterial blood gas; $\mathrm{AHRF}=$ acute hypercapnic respiratory failure; $\mathrm{BMI}=$ body mass index; $\mathrm{COPD}=$ chronic obstructive pulmonary disease; $C W D=$ chest wall deformity; DMD = Duchenne muscular dystrophy; EPAP = expiratory positive airways pressure; GCS = Glasgow coma score; ICU = intensive care unit; IMV = invasive mechanical ventilation; IPAP = inspiratory positive airways pressure; IV = intravenous; $\mathrm{KS}=$ kyphoscoliosis; $\mathrm{NIV}=$ non-invasive ventilation; $\mathrm{NM}=$ neuromuscular; $\mathrm{OHS}=$ obesity hypoventilation syndrome; OSA = obstructive sleep apnoea; PEEP = positive end expiratory pressure; $\mathrm{PS}=$ pressure support; $\mathrm{RR}=$ respiratory rate; $\mathrm{VC}=$ vital capacity Adapted with permission from Davidson AC, Banham S, Elliott M et al. BTS/ICS guideline for the ventilatory management of acute hypercapnic respiratory failure in adults. Thorax 2016;71 (Suppl 2):ii1-35. ${ }^{6}$

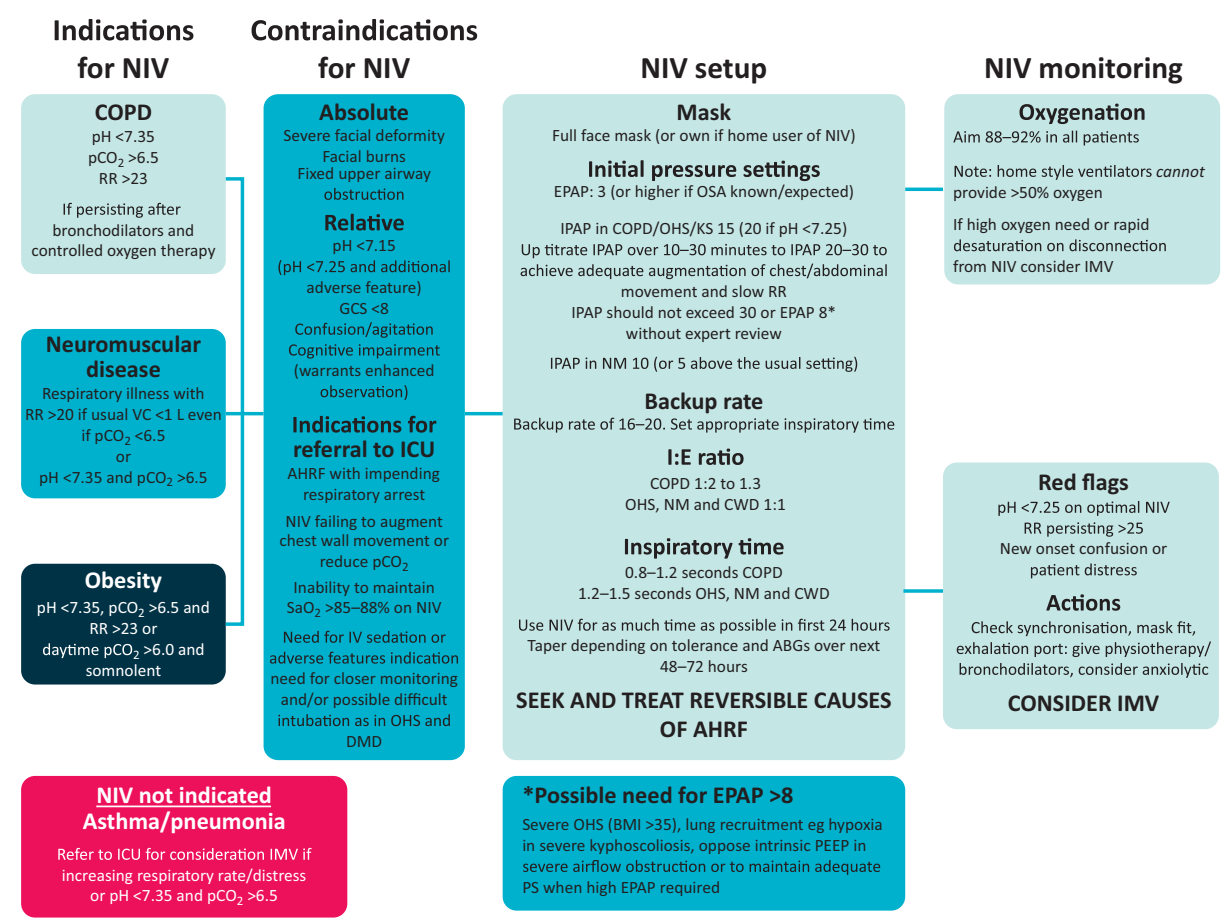

Some ventilators are equipped with an integral blender, which both ensures accurate delivery of $\mathrm{O}_{2}$ and allows delivery of a higher $\mathrm{FiO}_{2}$ when necessary. With an increasing level of IPAP the oxygen flow rate may need to be increased, but it should be noted that higher flow rates may interfere with ventilator triggering, leading to patient ventilator asynchrony. ${ }^{19}$ There is emerging evidence about non-inferiority of high flow nasal oxygen over NIV in hypoxaemic respiratory failure but its role in AHRF is still unclear. ${ }^{20,21}$

One study showed that NIV could be discontinued in AECOPD once physiological stability was obtained but this needs to be confirmed in other studies. ${ }^{22}$ Expert consensus recommends that NIV should be used as much as possible in the first 24 hours, with gradual reduction of support over the next 2 days. ${ }^{6}$ It can be stopped sooner if the patient is clinically improved, the acidosis resolved and $\mathrm{PCO}_{2}$ normalised.

\section{What to do when NIV fails}

Most of the evidence is from AECOPD. A number of studies have shown that intubation after a failed trial of NIV carries a worse prognosis than intubation from the outset. ${ }^{23-27}$ As NIV is indicated for most patients with an AECOPD, intubation will usually be considered after a failed trial of NIV. The reason why NIV has failed is important. ${ }^{14}$ Failure to improve at an early stage is usually due to technical factors eg mask intolerance, inadequate pressure support, excessive mask leak, patient ventilator asynchrony or agitation (Table 2). These are all potentially correctable but, if not, more effective ventilation may be delivered through a different interface, eg an endotracheal tube.

However if despite optimally applied NIV blood gases fail to improve the most likely explanation, in the absence of a potentially reversible cause, is that the underlying chronic lung disease is very severe and that any form of ventilation, even via an endotracheal tube, is unlikely to be successful. ${ }^{28}$
A decision about what should happen if NIV fails should be made when NIV is started. A decision to proceed to invasive mechanical ventilation (IMV) may be made, but this should be reviewed at regular intervals. An initial decision for full escalation

\section{Table 2. Technical issues: a guide for when non-}

invasive ventilation is failing

\begin{tabular}{|c|c|c|}
\hline Problem & Cause(s) & Solution (s) \\
\hline \multirow[t]{2}{*}{$\begin{array}{l}\text { Ventilator cycling } \\
\text { independently of } \\
\text { patient effort }\end{array}$} & $\begin{array}{l}\text { Inspiratory trigger } \\
\text { sensitivity is too } \\
\text { high }\end{array}$ & Adjust trigger \\
\hline & $\begin{array}{l}\text { Excessive mask } \\
\text { leak }\end{array}$ & Reduce mask leak \\
\hline \multirow{3}{*}{$\begin{array}{l}\text { Ventilator not } \\
\text { triggering despite } \\
\text { visible patient } \\
\text { effort }\end{array}$} & \multirow{2}{*}{$\begin{array}{l}\text { Excessive mask } \\
\text { leak }\end{array}$} & Reduce mask leak \\
\hline & & Adjust trigger \\
\hline & $\begin{array}{l}\text { Inspiratory trigger } \\
\text { sensitivity too low }\end{array}$ & $\begin{array}{l}\text { For NM patients } \\
\text { consider switch to PCV }\end{array}$ \\
\hline $\begin{array}{l}\text { Inadequate chest } \\
\text { expansion despite } \\
\text { apparent triggering }\end{array}$ & $\begin{array}{l}\text { Inadequate tidal } \\
\text { volume }\end{array}$ & $\begin{array}{l}\text { Increase IPAP. In NM } \\
\text { or chest wall disease } \\
\text { consider longer Ti }\end{array}$ \\
\hline \multirow{2}{*}{$\begin{array}{l}\text { Chest/abdominal } \\
\text { paradox }\end{array}$} & \multirow{2}{*}{$\begin{array}{l}\text { Upper airway } \\
\text { obstruction }\end{array}$} & Avoid neck flexion \\
\hline & & Increase EPAP \\
\hline $\begin{array}{l}\text { Premature } \\
\text { expiratory effort by } \\
\text { patient }\end{array}$ & $\begin{array}{l}\text { Excessive Ti or } \\
\text { IPAP }\end{array}$ & Adjust as necessary \\
\hline
\end{tabular}

$E P A P=$ expiratory positive airway pressure; IPAP = inspiratory positive airway pressure; NIV = non-invasive ventilation; NM = neuromuscular; $\mathrm{PCV}=$ pressure-controlled ventilation; $\mathrm{Ti}=$ duration of inspiration. Reproduced with permission from Davidson AC, Banham S, Elliott M et al. BTS/ICS guideline for the ventilatory management of acute hypercapnic respiratory failure in adults Thorax 2016;71 (Suppl 2):ii1-35. ${ }^{6}$ 
Box 1. Questions to determine whether escalation to invasive mechanical ventilation is appropriate if non-invasive ventilation is failing

Has non-invasive ventilation been delivered optimally (in terms of quality of mask fit, patient-ventilator synchrony, and appropriate escalation of pressures)?

o If not, adjust or change interface and make appropriate changes to ventilator settings

How long has the patient been in hospital?

o The longer the patient has been in hospital, the less likely a favourable outcome with non-invasive ventilation

Are any factors still potentially reversible?

o If not, there is a risk of prolonging the dying process

What was the patient's functional status before admission?

o A poor functional status is associated with a worse outcome

The more yes answers, the less likely a successful outcome will be reached even with invasive mechanical ventilation. Reproduced with permission from Bourke SC, Piraino T, Pisani L, Brochard L, Elliott MW. Beyond the guidelines for noninvasive ventilation in acute respiratory failure: implications for practice. Lancet Respir Med 2018:6:935-47. ${ }^{14}$

may no longer be appropriate a few days later if the patient deteriorates or fails to improve despite optimally applied NIV. AHRF developing, or worsening, after admission also carries a worse prognosis. ${ }^{2}$

Clinicians tend to underestimate the likelihood of a successful outcome from IMV particularly in those with apparently the worst prognosis. ${ }^{29}$ Prognostic tools such as the DECAF score ${ }^{30}$ aid, but cannot replace, clinical decision making; decisions must always be made on an individual basis. It is important for patients and relatives to understand that successful ventilation will at best only get the patient back to their premorbid level of function.

Factors which suggest that IMV may not be appropriate are summarised in Box 1, the more yes answers the less the likelihood of a successful outcome even with IMV.

\section{Complications}

Complications are rare with acute NIV. Care should be taken not to over-tighten the mask; this can lead to nasal bridge ulceration. Aerophagia and gastric distension may occur with higher inspiratory pressures; a nasogastric tube may relieve the discomfort. Very rarely acute pneumothorax can develop. Sudden deterioration with desaturation or chest pain should trigger an urgent chest X-ray; if possible NIV should be discontinued temporarily until a pneumothorax has been excluded.

\section{Prognosis and follow-up}

Presentation with AHRF is a poor prognostic marker irrespective of the underlying diagnosis. Recent studies in COPD suggest that domiciliary NIV might reduce readmissions and improve outcomes if the patient remains hypercapnic at 2 weeks post exacerbation. ${ }^{31}$ In NMDs or CWD, long term domiciliary ventilation is almost always indicated following an episode of AHRF. Most patients with OHS can be managed with domiciliary CPAP. In one study, patients with $\mathrm{OHS}$, even with significant hypercapnia ( $\geq 8 \mathrm{kPa}$ ) presenting acutely showed similar $\mathrm{PaCO}_{2}$ at 3 months with NIV and CPAP. ${ }^{32}$ In some patients, resolution of hypercapnia may occur after the acute event and there may be no need for respiratory support. A proportion will have obstructive sleep apnoea requiring treatment independently of the $\mathrm{PaCO}_{2}$. In all cases, patients who have received NIV acutely should be assessed within 2 to 6 weeks by a specialist.

\section{Conflicts of interest}

Dr Mark W Elliott has received honoraria, subsistence and travel expenses from Resmed, Philips Respironics, and Fisher and Paykel.

\section{References}

1 Davies M, Allen M, Bentley A et al. British Thoracic Society Quality Standards for acute non-invasive ventilation in adults. BMJ Open Respir Res 2018;5:e000283.

2 Roberts CM, Stone RA, Buckingham RJ, Pursey NA, Lowe D. Acidosis, non-invasive ventilation and mortality in hospitalised COPD exacerbations. Thorax 2011;66:43-8.

3 British Thoracic Society. BTS national audit reports. London: BTS.

4 The National Confidential Enquiry into Patient Outcome and Death (2017). Inspiring change. A review of the quality of care provided to patients receiving acute non-invasive ventilation. London: NCEPOD, 2017. www.ncepod.org.uk/2017report2/downloads/ InspiringChange_FullReport.pdf.

5 O'Driscoll BR, Howard LS, Earis ], Mak V. BTS guideline for oxygen use in adults in healthcare and emergency settings. Thorax 2017;72(Suppl 1):ii1-90.

6 Davidson AC, Banham S, Elliott M et al. BTS/ICS guideline for the ventilatory management of acute hypercapnic respiratory failure in adults. Thorax 2016;71 (Suppl 2):ii1-35.

7 Rochwerg B, Brochard L, Elliott MW et al. Official ERS/ATS clinical practice guidelines: noninvasive ventilation for acute respiratory failure. Eur Respir ] 2017;50.

8 Shahrizaila N, Kinnear WJ, Wills AJ. Respiratory involvement in inherited primary muscle conditions. J Neurol Neurosurg Psychiatry 2006;77:1108-15.

9 Lad TS. An 'acute' presentation of motor neuron disease. Acute Med 2011;10:140-1.

10 Vital FM, Ladeira MT, Atallah AN. Non-invasive positive pressure ventilation (CPAP or bilevel NPPV) for cardiogenic pulmonary oedema. Cochrane Database Syst Rev 2013:CD005351.

11 Gray A, Goodacre S, Newby DE et al. Noninvasive ventilation in acute cardiogenic pulmonary edema. N Engl J Med 2008;359:142-51.

12 Confalonieri M, Potena A, Carbone G et al. Acute respiratory failure in patients with severe community-acquired pneumonia. A prospective randomized evaluation of noninvasive ventilation. Am J Respir Crit Care Med 1999;160:1585-91.

13 Diaz GG, Alcaraz AC, Talavera JCP et al. Noninvasive positive-pressure ventilation to treat hypercapnic coma secondary to respiratory failure. Chest 2005:127:952-60.

14 Bourke SC, Piraino T, Pisani L, Brochard L, Elliott MW. Beyond the guidelines for non-invasive ventilation in acute respiratory failure: implications for practice. Lancet Respir Med 2018;6:935-47.

15 Parker K, Perikala V, Aminazad A et al. Models of care for noninvasive ventilation in the Acute COPD Comparison of three Tertiary hospitals (ACT3) study. Respirology 2018;23:492-7.

16 Plant PK, Owen J, Elliott MW. One year period prevalance study of respiratory acidosis in acute exacerbation of COPD; implications for the provision of non- invasive ventilation and oxygen administration. Thorax 2000;55:550-4.

17 Plant PK, Owen JL, Elliott MW. Non-invasive ventilation in acute exacerbations of chronic obstructive pulmonary disease: long term survival and predictors of in-hospital outcome. Thorax 2001;56:708-12. 
18 Confalonieri M, Garuti G, Cattaruzza MS et al. A chart of failure risk for noninvasive ventilation in patients with COPD exacerbation. Eur Respir ] 2005;25:348-55.

19 Ghosh D, Elliott MW. Looking under the bonnet of patientventilator asynchrony during noninvasive ventilation: does it add value? ERJ Open Res 2017;3.

20 Doshi P, Whittle JS, Bublewicz M et al. High-velocity nasal insufflation in the treatment of respiratory failure: a randomized clinical trial. Ann Emerg Med 2018;72:73-83.e5.

21 Frat JP, Thille AW, Mercat A et al. High-flow oxygen through nasal cannula in acute hypoxemic respiratory failure. $N$ Engl J Med 2015;372:2185-96.

22 Ferrer M, Sellares ], Torres A. NIV in withdrawal from mechanical ventilation. Eur Respir Monogr 2012(55):191-205.

23 Chandra D, Stamm JA, Taylor B et al. Outcomes of noninvasive ventilation for acute exacerbations of chronic obstructive pulmonary disease in the United States, 1998-2008. Am J Respir Crit Care Med 2012;185:152-9.

24 Lindenauer PK, Stefan MS, Shieh MS et al. Hospital patterns of mechanical ventilation for patients with exacerbations of COPD. Ann Am Thorac Soc 2015;12:402-9.

25 Stefan MS, Nathanson BH, Higgins TL et al. Comparative effectiveness of noninvasive and invasive ventilation in critically ill patients with acute exacerbation of chronic obstructive pulmonary disease. Crit Care Med 2015;43:1386-94.

26 Mehta AB, Douglas IS, Walkey AJ. Hospital noninvasive ventilation case volume and outcomes of acute exacerbations of chronic obstructive pulmonary disease. Ann Am Thorac Soc 2016:13:1752-9.
27 Lindenauer PK, Stefan MS, Shieh MS et al. Outcomes associated with invasive and noninvasive ventilation among patients hospitalized with exacerbations of chronic obstructive pulmonary disease. JAMA Intern Med 2014;174:1982-93.

28 Elliott MW, Nava S. Noninvasive ventilation for acute exacerbations of chronic obstructive pulmonary disease: 'Don't think twice, it's alright!'. Am J Respir Crit Care Med 2012;185:121-3.

29 Wildman MJ, Sanderson C, Groves ] et al. Implications of prognostic pessimism in patients with chronic obstructive pulmonary disease (COPD) or asthma admitted to intensive care in the UK within the COPD and asthma outcome study (CAOS): multicentre observational cohort study. BMJ 2007:335:1132.

30 Steer J, Gibson J, Bourke SC. The DECAF Score: predicting hospital mortality in exacerbations of chronic obstructive pulmonary disease. Thorax 2012;67:970-6.

31 Murphy PB, Rehal S, Arbane $\mathrm{G}$ et al. Effect of home noninvasive ventilation with oxygen therapy vs oxygen therapy alone on hospital readmission or death after an acute COPD exacerbation: A randomized clinical trial. JAMA 2017:317:2177-86.

32 Howard ME, Piper AJ, Stevens B et al. A randomised controlled trial of CPAP versus non-invasive ventilation for initial treatment of obesity hypoventilation syndrome. Thorax 2017;72:437-44.

Address for correspondence: Dr Dipansu Ghosh, Sleep and NIV Services, St James's University Hospital, Beckett Street, Leeds, West Yorkshire LS9 7TF, UK.

Email: dipansughosh@nhs.net

\section{Royal College of Physicians}
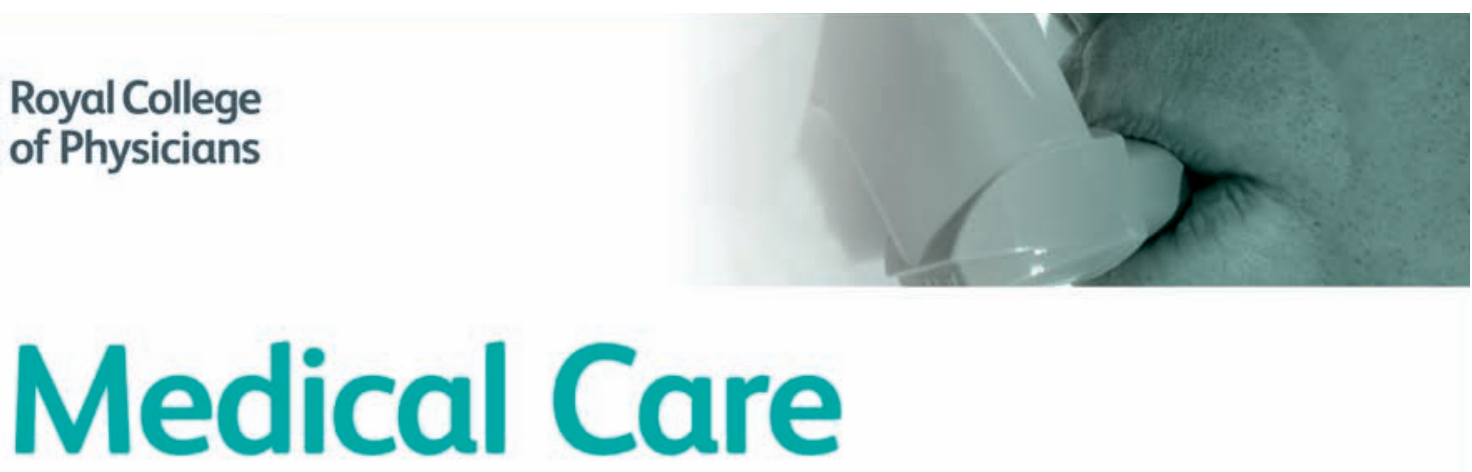

\section{Are you involved in planning respiratory medicine services?}

\begin{abstract}
Medical Care is the online evolution of the well-known RCP publication Consultant physicians working with patients. Written by leading medical specialty experts, it is a comprehensive web-based resource for the efficient and effective design of medical services covering all the specialties, including respiratory medicine.
\end{abstract}

\section{www.rcpmedicalcare.org.uk}

The resource looks in detail at the services delivered by respiratory medicine, including:

$>$ inpatient services

> general outpatient services

> specialist clinics, including asthma and lung cancer

$>$ procedural services

$>$ ventilation services.

Medical Care has been designed to help those involved in the planning and provision of medical services to get a clearer picture of the specialty services that need to be in place to provide great patient care. 